\title{
Effect of post-cure conditions on interfacial properties of glass fiber/vinylester composites
}

\author{
T. Ota ${ }^{1} \&$ T. Matsuoka ${ }^{2}$ \\ ${ }^{1}$ Toyama National College of Technology, Japan \\ ${ }^{2}$ Doshisha University, Japan
}

\begin{abstract}
Microdroplet tests were carried out in order to investigate the effect of post-cure (PC) conditions on the interfacial properties of glass fiber/vinylester composites. Microdroplet test specimens were postcured at $80^{\circ} \mathrm{C}$ for a period varying from $4 \mathrm{~h}$ to $24 \mathrm{~h}$. The load increased linearly up to the maximum pull-out load, when the load reached the critical load, beyond which the load reduced rapidly under all post-cure conditions. Shear debonding occurred in the fiber/matrix interface at the maximum pull-out load. The maximum load increased with a longer embedded length under all post-cure conditions. In addition, the maximum load was larger with a longer post-cure time. In the cases of $\mathrm{PC}$ for $48 \mathrm{~h}$ at room temperature plus $8 \mathrm{~h}$ and $16 \mathrm{~h}$ at $80^{\circ} \mathrm{C}$, designated as $\mathrm{PC} 8 \mathrm{~h}$ and $\mathrm{PC} 16 \mathrm{~h}$, respectively, debonding occurred at a short embedded length in contrast to other post-cure conditions. The post-cure conditions PC8h and PC16h improved the interfacial shear strength (IFSS) in comparison with that PC4h. The post-cure condition PC24h decreased the IFSS compared with PC16h. The sizes of the meniscus for both PC8h and PC16h were larger than those for both PCOh and PC4h. The surface of glass fiber was relatively smooth under all post-cure conditions. The residual thermal stress was increased due to post-cure. The mechanical anchoring contributed to the increase in the IFSS.

Keywords: post-cure, glass/vinylester composites, microdroplet test, interfacial properties, mechanical anchoring.
\end{abstract}

\section{Introduction}

Fiber reinforced polymeric matrix (FRP) composites are widely used in the aircraft industry and infrastructure because of excellent specific strength, specific 
stiffness and corrosive resistance. Thermosetting resins such as epoxy, unsaturated polyester and vinylester account for the majority of resins used in primary structural materials. FRP, the matrix of which is a thermosetting resin, is subjected to a heat history during the fabrication process due to the promotion of the cross-linking reaction on the thermosetting resin. Post-cure is conducted in order to enhance the mechanical properties of the thermosetting resin after curing [1]. However, most manufacturers have recognized that they could achieve the goal of enhancing the durability of FRP if post-cure contributed to the improvement of mechanical properties. However, they have not embarked into a new investigation, even though it is important to investigate the effect of the post-cure conditions on the mechanical properties of FRP.

There has been some research on the effect of post-cure or annealing on the mechanical properties of FRP [2-5]. Most of this research suggested that postcure has two potential effects: (1) the difference in thermal expansion between the fiber and the matrix, resulting in residual stress and a decrease of interfacial strength; (2) the establishment of covalent bonds across the interface, resulting in an increase in the bond strength. Ogi [6] predicted the transverse crack density by means of a Weibull's probabilistic failure model taking into account the residual stress caused by the post-cure. Moreover, it is well known that the unreacted parts shrink due to post-cure if the parts exist in the matrix. However, the research on the effect of post-cure on the mechanical properties of FRP, which takes into account the unreacted parts of matrix, requires investigation.

In this work, the relationship between fiber/matrix interactions and the interfacial shear strength of glass fiber/vinylester composites containing unreacted parts in the matrix is investigated by means of the microdroplet technique. The microdroplet technique was used to determine the interfacial shear strength (IFSS) for several resins under varying post-cure times.

\section{Experimental procedure}

\subsection{Specimen preparation}

The glass fiber used for the microdroplet test was monofilament glass fiber extracted from glass roving (RS110QL; Nitto Boseki Co. Ltd.). The fiber had an average diameter of $20 \mu \mathrm{m}$. Vinylester resin (Diclite UE-3505; Dainihon Ink \& Chemical Co. Ltd.), methylethylketoneperoxide and cobalt napthenate $(6 \%$ solution) were used as the matrix, curing agent and room temperature catalyst, respectively. The specimen used to perform the microdroplet test is illustrated in fig. 1. Firstly, a monofilament glass fiber was glued onto drawing paper. Then, a very small amount of vinylester resin was dropped onto the monofilament by use of a thin needle. The specimens were placed in a chamber for at least 48 hours at room temperature $\left(23 \pm 2^{\circ} \mathrm{C}\right)$ and then in an oven at $80^{\circ} \mathrm{C}$ according to several time schedules, as shown in table 1 . The latter lists the post-cure conditions for vinylester resin and their designations in this study. The produced drops were checked with a digital microscope (BS-8000III, Sonic Co. Ltd.). The length for 


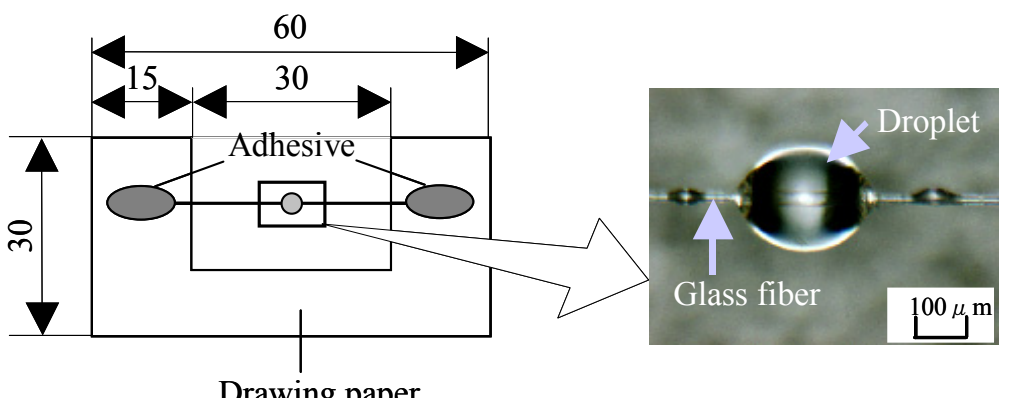

Figure 1: Dimension of the microdroplet test specimen.

Table 1: Cure conditions for glass fiber/vinylester composites.

\begin{tabular}{c|c}
\hline Type & \multicolumn{1}{|c}{ Cure schedule } \\
\hline PC0h & $48 \mathrm{~h} @$ R.T. \\
PC4h & $48 \mathrm{~h} @$ R.T. $+4 \mathrm{~h} @ 80^{\circ} \mathrm{C}$ \\
PC8h & $48 \mathrm{~h} @$ R.T. $+8 \mathrm{~h} @ 80^{\circ} \mathrm{C}$ \\
PC16h & $48 \mathrm{~h} @$ R.T. $+16 \mathrm{~h} @ 80^{\circ} \mathrm{C}$ \\
PC24h & $48 \mathrm{~h} @$ R.T. $+24 \mathrm{~h} @ 80^{\circ} \mathrm{C}$ \\
\hline
\end{tabular}

*R.T. is room temperature.

which the glass fiber was embedded in the droplet of resin was controlled in the range from $200 \mu \mathrm{m}$ to $400 \mu \mathrm{m}$.

\subsection{Experiments}

The mechanical properties of the resins, which have different post-cure conditions, were measured with dumbbell shaped specimens, fitted on a universal material testing machine (model 4467, Instron), at room temperature $\left(23 \pm 2{ }^{\circ} \mathrm{C}\right.$ ), at $1.0 \mathrm{~mm} / \mathrm{min}$ crosshead speed. The coefficient of thermal expansion, $\alpha_{m}$, of the resin was measured in an oven (DV600, Yamato Scientific Co. Ltd.) using a strain gauge by means of the active-dummy gauge method. Microdroplet tests were performed using a universal material testing machine (Ez-Graph; Shimadzu Co. Ltd.). Fig. 2 shows the microdroplet specimen and the jig fixed to the testing machine. The jig was set to the lower chuck of the testing machine. The microdroplet specimen was inserted into a small gap of a pair of microvises and the one end of the microdroplet specimen was connected to the upper chuck of that machine as shown in fig. 2. As the screw-servomoter ran, the load cell and upper chuck attached to the crosshead moved upward. Due to this movement, the droplet was pulled out from the monofilament. During the test, load and displacement were measured by load cell and the amount of crosshead movement, respectively. The monofilament was pulled at a crosshead speed of $0.5 \mathrm{~mm} / \mathrm{min}$ at room temperature $\left(23 \pm 2^{\circ} \mathrm{C}\right)$. The interfacial shear strength, $\tau$, can be calculated from 


$$
\tau=\frac{F}{\pi d_{f} l}
$$

where $F$ is pull-out load, $d_{f}$ is the fiber diameter and $l$ is the fiber embedded length.
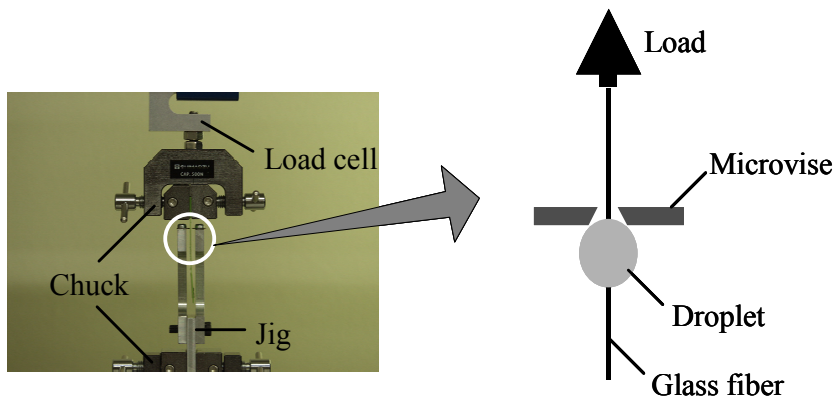

Figure 2: $\quad$ Microdroplet specimen fixed to the testing machine.

\section{Results and discussion}

The typical load-displacement curves of the microdroplet specimens with an embedded length of $0.250 \mathrm{~mm}$ can be seen in figs 3(a)-(e). Each curve indicates that the load increases linearly up to a maximum pull-out load, $F_{\max }$, when the load reaches a critical load, i.e. $F_{\max }$, beyond which the load reduces rapidly. Miller et al. [7] showed force traces for the three possible results of a shear test such as a microbond test. The fracture patterns, which are shear debonding, droplet slippage through the slit and fiber breakage, were distinguished in the load-displacement behavior during the test. In the results, shear debonding occurs at the interface between the fiber and the matrix at the maximum pull-out force, $F_{\max }$, without dependence on the post-cure condition. In other words, the interface failed at the same time as the glass fiber was pulled out from the microdroplet. Thus, the interfacial shear strength, $\tau$, was calculated from $F_{\max }$, the embedded length and the fiber diameter according to eqn (1).

In order to evaluate the effect of post-cure time on the stress transfer from the fiber to the matrix, the relationship between the maximum load and the embedded length are shown in figs 4(a)-(e). The maximum load at which a glass fiber was pulled out from a droplet was used in order to graph the relationship. Under all post-cure conditions, the maximum load increased with longer embedded length in spite of the scatter of the data. In addition, it is clear that the maximum load was larger with a longer post-cure time. In the cases of PC8h and PC16h, the fiber/matrix debonding occurred at a short embedded length in contrast to other post-cure conditions, as shown in figs 4(c) and (d). In other words, these results might show that post-cure contributed to enhancing the stress transfer from the matrix to the fiber. However, the relationship between the maximum load and the embedded length for PC24h was slightly different as 

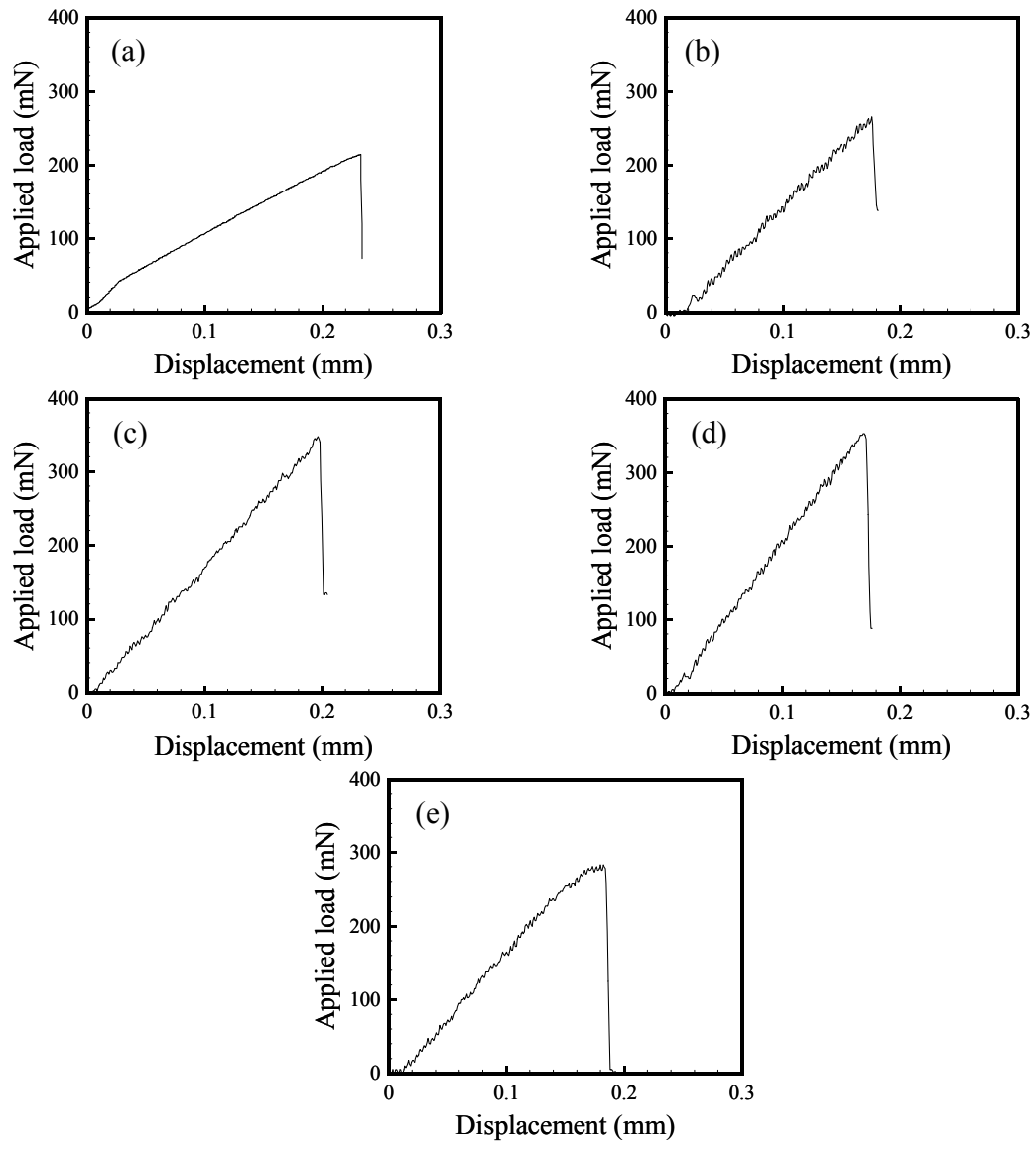

Figure 3: Load-displacement curves of glass fiber/vinylester composites in the microdroplet test: (a) PC0h, (b) PC4h, (c) PC8h, (d) PC16h, (e) PC24h.

compared with that for PC8h and PC16h, even though the post-cure was sufficient for curing the resin, as shown in fig. 4(e).

The relationship between the interfacial shear strength and the embedded length is shown in fig. 5. The black circle indicates the symbol for the mean value of the interfacial shear strength. The mean value was computed by fitting the data to the Weibull distribution. A post-cure condition such as PC8h improved the IFSS by $30 \%$ in comparison with that such as PC4h, while the IFSS of PC16h had almost the same value as that of PC8h. However, a post-cure condition such as PC24h decreased the IFSS by $30 \%$ compared with that such as PC16h. The SEM images of the microdroplet specimens with an embedded length of $0.250 \mathrm{~mm}$ after debonding are shown in figs 6(a)-(e). The sizes of the meniscus for both $\mathrm{PC} 8 \mathrm{~h}$ and $\mathrm{PC} 16 \mathrm{~h}$ are larger than those for both $\mathrm{PCOh}$ and 

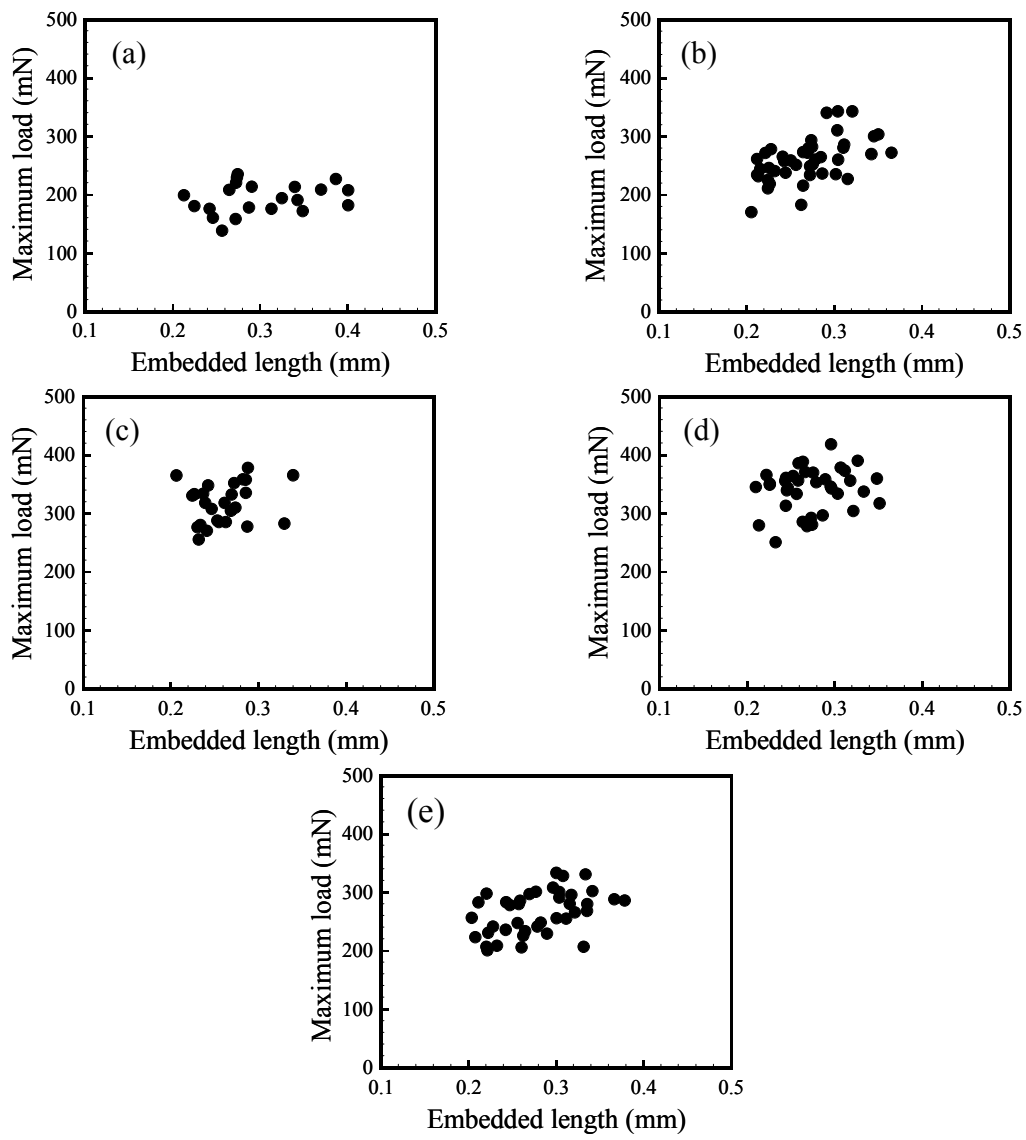

Figure 4: Relationship between maximum load and embedded length: (a) PC0h, (b) PC4h, (c) PC8h, (d) PC16h, (e) PC24h.

PC4h, while the meniscus of PC24h is almost same size as that of both PCOh and PC4h. This result may indicate that the post-cure can improve the interaction at the interface between the fiber and the matrix. However, the surface of the glass fiber is relatively smooth under all post-cure conditions. In general, the surface of the glass fiber is treated with silane coupling agents in order to enhance the bond strength at the fiber/matrix interface. If chemical bonds do not exist between the fiber and the matrix, the interfacial shear strength would be attributed to the physical bonding such as Van der Waal's interactions and the mechanical anchoring resulting from the difference in thermal expansion between the fiber and the matrix that gives rise to a pressure at the interface [8, 9]. In other words, since the fiber and the matrix have different expansion coefficients, residual stresses may develop at the fiber/matrix interface upon 


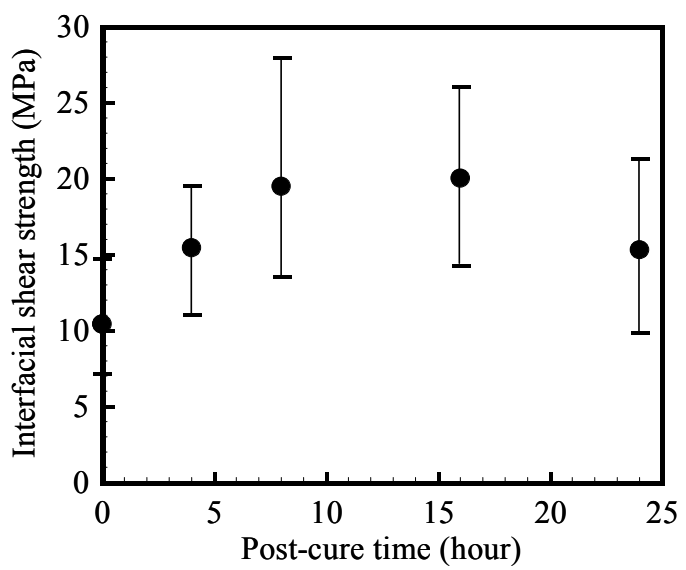

Figure 5: Relationship between interfacial shear strength and post-cure time.

cooling to room temperature. The stress $P$, due to radial shrinkage can be calculated by the following expression [10]

$$
P=\frac{\left(\alpha_{m}-\alpha_{f}\right) \Delta T E_{m}}{\left(1+v_{m}\right)+\left(1-v_{f}\right) E_{m} / E_{f}}
$$

where $\alpha$ is the thermal expansion coefficient. $v$ the Poisson's ratio, $E$ the Young's modulus and $\Delta T$ the temperature difference between the glass transition temperature and the room temperature. The subscripts $f, m$ denotes the fiber and the matrix, respectively. The mechanical properties used in this calculation are shown in table 2. The glass transition temperature of vinylester resin was calculated from the result of a previous study [11]. The Young's modulus of the vinylester resin was determined by analysis of the stress-strain curves for five post-cure conditions. The relationship between the residual stress and the postcure time is shown in fig. 7. This figure shows that post-cure tends to increase the residual stress until the post-cure time reaches 16 hours. In particular, the glass/vinylester system of $\mathrm{PC} 8 \mathrm{~h}$ and $\mathrm{PC} 16 \mathrm{~h}$ represent the increase in stress by $30 \%$ in comparison to that of PC4h. This tendency is similar to that of the result of the IFSS, as shown in fig. 5. For thermosetting resin, the matrix shrinks due to the promotion of the cross-link reaction. The shrinkage might be attributed to the increase in the contact area between the fiber and the matrix; at the same time, it would enhance the mechanical anchoring at the fiber/matrix interface. A previous study [11] revealed that plain woven GFRP cured in a short time at a constant temperature has the unreacted parts of the matrix. Therefore, post-cure conditions such as PC8h and PC16h may contribute to the improvement of the mechanical anchoring. Moreover, the mechanical anchoring could contribute to the increase in the IFSS. However, the post-cure condition PC24h decreased the 
pressure by $6 \%$ in contrast to that of PC16h. This reduction of IFSS might be attributed to the ambient effect such as high temperature. Further verification of this reduction will be carried out in the future.
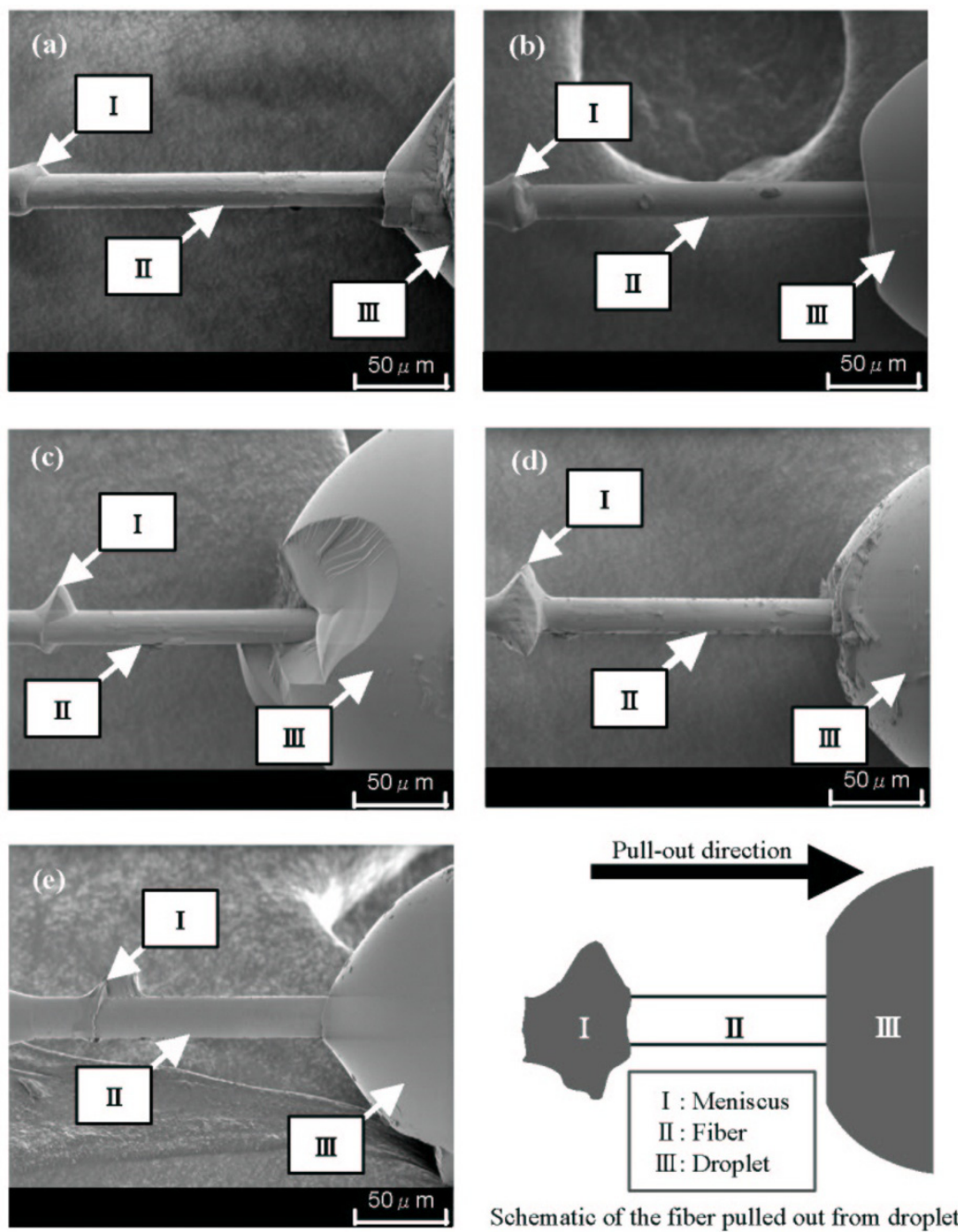

Schematic of the fiber pulled out from droplet.

Figure 6: SEM images of microdroplet specimens after debonding: (a) PCOh, (b) PC4h, (c) PC8h, (d) PC16h, (e) PC24h.

\section{Conclusions}

Microdroplet tests were conducted in order to investigate the effect of post-cure condition on the interfacial properties of glass/vinylester composites. The major results are summarized as follows: 
Table 2: $\quad$ Mechanical properties of glass fiber and vinylester resin.

\begin{tabular}{l|r|rrrrr}
\hline & \multirow{5}{|c|}{ Vinylester resin } \\
\cline { 3 - 6 } & Glass fiber & PC0h & PC4h & PC8h & PC16h & PC24h \\
\hline Young's modulus $\left(\mathrm{E}_{f}\right.$ or $\left.\mathrm{E}_{m}\right)(\mathrm{GPa})$ & 72.5 & 2.8 & 3.3 & 3.7 & 3.7 & 3.5 \\
Axial CTE* $\left(\alpha_{f}\right.$ or $\left.\alpha_{m}\right)\left(10^{-6} /{ }^{\circ} \mathrm{C}\right)$ & 5 & 51 & 41 & 39 & 39 & 39 \\
Poisson's ratio $\left(\nu_{f}\right.$ or $\left.v_{m}\right)$ & 0.17 & 0.40 & 0.39 & 0.38 & 0.38 & 0.38 \\
Glass transition temperature $\left(\mathrm{T}_{\mathrm{g}}\right)\left({ }^{\circ} \mathrm{C}\right)$ & - & 55.2 & 84.5 & 102.7 & 102.3 & 102.2 \\
Temperature difference $(\Delta T)\left({ }^{\circ} \mathrm{C}\right)$ & - & 30.2 & 59.5 & 77.7 & 77.3 & 77.2 \\
\hline
\end{tabular}

* CTE is Coefficient of Thermal Expansion.

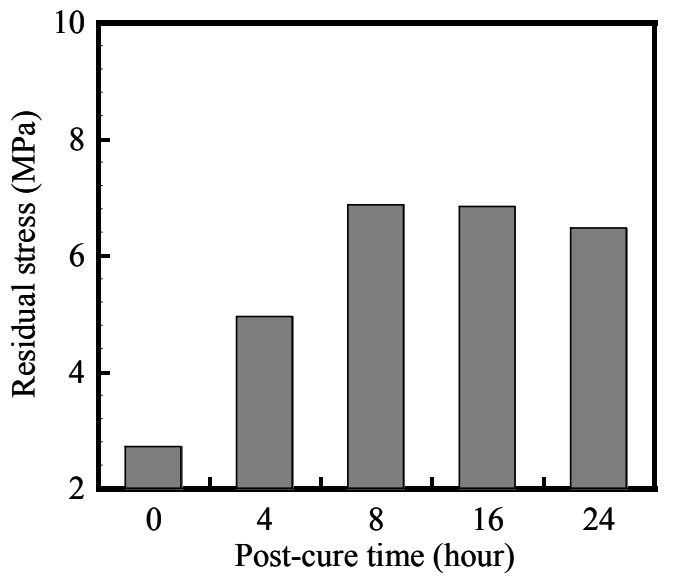

Figure 7: Relationship between residual stress and post-cure time.

1) The load increased linearly up to a maximum pull-out load, when the load reached a critical load, thereafter the load reduced rapidly under all postcure conditions. Shear debonding occurred at the interface between the fiber and the matrix at a maximum pull-out load.

2) The maximum force increased with a longer embedded length under all post-cure conditions. In addition, the maximum force was larger with a longer post-cure time. In the case of PC8h and PC16h, the fiber/matrix debonding occurred at a short embedded length in contrast to other postcure conditions.

3) The post-cure condition of PC8h and PC16h improved the IFSS by $30 \%$ in comparison with that of PC4h, while the IFSS of PC16h had almost the same value as that of PC8h. On the contrary, the post-cure condition of PC24h decreased the IFSS by $30 \%$ as compared with that of PC16h.

4) The size of the meniscus for both PC8h and PC16h was larger than that for both $\mathrm{PCOh}$ and $\mathrm{PC} 4 \mathrm{~h}$, while the meniscus of PC24h had almost the same size as that of both PCOh and PC4h. However, the surface of the glass fiber is relatively smooth under all post-cure conditions. 
5) The glass/vinylester system of $\mathrm{PC} 8 \mathrm{~h}$ and $\mathrm{PC} 16 \mathrm{~h}$ represented an increase in residual stress by $30 \%$ in comparison to that of $\mathrm{PC} 4 \mathrm{~h}$. The mechanical anchoring contributed to an increase in the interfacial shear strength.

\section{Acknowledgement}

This study was supported by the Research and Development Center for Composite Materials at Doshisha University.

\section{References}

[1] Matsushita, Y., Novel theory of cross-link reaction, Part 1. Kogyouzairyou, 47(2), pp. 82-85, 1999.

[2] Lindsey, K.A., Rudd, C.D. \& Fraser, I.M., Effect of post-cure on mechanical properties of glass fibre-urethane methacrylate composites. Journal of Materials Science Letters, 12, pp. 894-897, 1993.

[3] Tucker, R., Compston, P. \& Jar, P.-Y.B., The effect of post-cure duration on the mode I interlaminar fracture toughness of glass-fibre reinforced vinylester. Composites Part A, 32(1), pp. 129-134, 2001.

[4] Kotaki, M., Kuriyama, T., Hamada, H., Maekawa, Z. \& Narisawa, I., Annealing effect in glass woven fabric composites, Part 1. Mode I and Mode II interlaminar fracture behavior. Composite Interface, 7(5)(6), pp. 363-383, 2001.

[5] Kotaki, M., Kuriyama, T., Hamada, H., Maekawa, Z. \& Narisawa, I., Annealing effect in glass woven fabric composites, Part 2. Bending properties. Composite Interfaces, 7(5)(6), pp. 385-397, 2001.

[6] Ogi, K., Effect of post-cure on mechanical properties of CF/Epoxy composites. Journal of the Society of Materials Science, Japan, 51(5), pp. 518-523, 2002.

[7] Miller, B., Muri, P. \& Rebenfeld, L., A microbond method for delamination of the shear strength of a fiber/resin interface. Composite Science and Technology, 28, pp. 17-32, 1987.

[8] Liao, Y.-T. \& Tung, I.-C., Properties of carbon fibre-polymer interfaces. Journal of Materials Science Letters, 10, pp. 272-275, 1991.

[9] Biro, D.A., McLean, P. \& Deslandes, Y., Application of the microbond technique: Characterization of carbon fiber-epoxy interfaces. Polymer Engineering and Science, 37(17), pp. 1250-1256, 1991.

[10] George, G. \& Gilbert, A.C., Photothermoelasticity: An exploratory study. Journal of Applied Mechanics ASME, 24, pp. 355-360, 1957.

[11] Ota, T., Matsuoka, T. \& Sakaguchi, K., Effect of post-cure time on mechanical properties of plain-woven glass fabric composites. Journal of the Society of Materials Science, Japan, 55(10), pp. 958-964, 2006. 